\title{
LIFE EXPECTANCY
}

\section{Age is just a number}

\section{The naked mole rat defies the Gompertz law and shows no sign of increased mortality risk as it gets older.}

\author{
HIRAM BELTRÁN-SÁNCHEZ AND CALEB FINCH
}

Related research article Ruby JG, Smith M, Buffenstein R. 2018. Naked mole rat mortality rates defy Gompertzian laws by not increasing with age. elife 7:e31157. DOI: 10.7554/eLife.31157 (c) Copyright Beltrán-Sánchez and Finch. This article is distributed under the terms of the Creative Commons Attribution License, which permits unrestricted use and redistribution provided that the original author and source are credited. analyze an existing data set of 3,299 naked mole rats across a 30-year timespan and found that they did not conform to the Gompertz-Makeham law. In fact, their mortality hazard did not increase as they got older. This is unprecedented for mammals - one would not expect a small rodent such as the naked mole rat to live for more than six years, let alone show the first signs of aging at a time double its predicted maximum lifespan.

Previous studies suggest that aging nonetheless creeps in: naked mole rats can accumulate oxidative damage in their cells and tissues (a sign of aging) and experience muscle wasting, and there is also some evidence for cancer (Edrey et al., 2011; Andziak et al., 2006; Taylor et al., 2017). This motivates further consideration of Ruby et al.'s demographic criteria so that we can understand why their data show an absence of Gompertz mortality accelerations.

It can be assumed that when no deaths are observed in a group, there is still a risk of mortality - it may just be very low. However, when the number of deaths is low, errors in the sampling method could bias the estimates of the Gompertz parameters (Promislow et alo, 1999). At its minimum measurable value, the death rate in a population is either 0 (no one dies) or 1 (a single individual dies). For the data studied by Ruby et al., this means that the minimum rate of mortality that can be accurately reported is $1 /$ 3,299: a baseline mortality of $\sim 0.0003$ per day. However, the baseline mortality reported in Ruby et al. is even lower (1/10,000 per day). This would indicate that their naked mole rat population is too small to correctly estimate the true mortality rate or the Gompertz parameters. In fact, sample sizes much larger than 3,299 would be needed to detect aging mortality acceleration. 
Another component of the Gompertz-Makeham model is the rate of aging, from which the mortality rate doubling time (that is, the time required for the mortality rate to double) can be calculated. For example, assuming that the mortality rate begins to speed up when the naked mole rat reaches maturity at six months of age, the rate of Gompertz aging can be calculated to be about 0.006 per year of age. This is far lower than values found in modern human populations, where the rate ranges from 0.07 to 0.09 per year of age (Finch et al., 2014). Based on this, the mortality rate doubling time would be 115 years for the naked mole rat, compared to eight years for most human populations (Finch, 1998; Finch et alo, 1990). This would suggest that unlike any other mammal, the naked mole rats have an extremely low rate of aging.

Its minimal age-related problems and long life-span make the naked mole rat an ideal candidate to study 'negligible senescence', a phenomenon that has been observed in a few species that reach advanced ages without increased mortality or disability (Finch, 2015). The study of Ruby et al. furthers our knowledge and provides a good framework for future studies to build upon.

Hiram Beltrán-Sánchez is in the Department of Community Health Sciences and California Center for Population Research, The University of California Los Angeles, Los Angeles, United States

Caleb E Finch is in the Leonard Davis School of Gerontology and Dornsife College, University of Southern California, Los Angeles, United States cefinch@usc.edu

(iD) http://orcid.org/0000-0002-7617-3958

Competing interests: The authors declare that no competing interests exist.

Published 24 January 2018

\section{References}

Andziak B, O'Connor TP, Qi W, DeWaal EM, Pierce A, Chaudhuri AR, Van Remmen H, Buffenstein R. 2006.
High oxidative damage levels in the longest-living rodent, the naked mole-rat. Aging Cell 5:463-471. DOI: https://doi.org/10.1111/j.1474-9726.2006.00237. x, PMID: 17054663

Edrey YH, Hanes M, Pinto M, Mele J, Buffenstein R. 2011. Successful aging and sustained good health in the naked mole rat: a long-lived mammalian model for biogerontology and biomedical research. ILAR Journal 52:41-53. DOI: https://doi.org/10.1093/ilar.52.1.41، PMID: 21411857

Finch CE, Beltrán-Sánchez H, Crimmins EM. 2014.

Uneven futures of human lifespans: reckonings from Gompertz mortality rates, climate change, and air pollution. Gerontology 60:183-188. DOI: https://doi. org/10.1159/000357672, PMID: 24401556

Finch CE, Pike MC, Witten M. 1990. Slow mortality rate accelerations during aging in some animals approximate that of humans. Science 249:902-905.

DOI: https://doi.org/10.1126/science.2392680,

PMID: 2392680

Finch CE. 1998. Variations in senescence and longevity include the possibility of negligible senescence. The Journals of Gerontology Series A: Biological Sciences and Medical Sciences 53:B235-B239. DOI: https://doi. org/10.1093/gerona/53A.4.B235, PMID: 18314551 Finch CE. 2015. Negligible Senescence, Chapter 7. In: Vijg J, Campisi J, Lithgow G (Eds). Molecular and Cellular Biology of Aging. Burlington, MA: Jones and Bartlett Learning.

Podlutsky AJ, Khritankov AM, Ovodov ND, Austad SN. 2005. A new field record for bat longevity. The Journals of Gerontology Series A: Biological Sciences and Medical Sciences 60:1366-1368. DOl: https://doi org/10.1093/gerona/60.11.1366, PMID: 16339320 Promislow DEL, Tatar M, Pletcher S, Carey JR. 1999. Below-threshold mortality: implications for studies in evolution, ecology and demography. Journal of Evolutionary Biology 12:314-328. DOI: https://doi.org/ 10.1046/j.1420-9101.1999.00037.x

Ruby JG, Smith M, Buffenstein R. 2018. Naked mole rat mortality rates defy Gompertzian laws by not increasing with age. eLife 7:31157. DOI: https://doi org/10.7554/eLife.31157

Taylor KR, Milone NA, Rodriguez CE. 2017. Four cases of spontaneous neoplasia in the naked mole-rat (Heterocephalus glaber), a putative cancer-resistant species. The Journals of Gerontology Series A:

Biological Sciences and Medical Sciences 72:38-43. DOI: https://doi.org/10.1093/gerona/glw047, PMID: 27129918 